\title{
DOI 10.26886/2414-634X.5(49)2021.4
}

UDC: $378.011 .3-051: 78: 37.041$

EVELOPMENT OF THE CREATIVITY OF ADOLESCENTS IN LEARNING MUSICAL ACTIVITIES

\section{Pan Qianyi}

https://orcid.org/0000-0002-1217-3190

e-mail: rain19901028@ gmail.com

M. P. Dragomanov National Pedagogical University, Kyiv, Ukraine

\section{Regina Savchenko}

https://orcid.org/0000-0002-4380-8777

e-mail: sarina_30@ukr.net

M. P. Dragomanov National Pedagogical University, Kyiv, Ukraine.

\section{Yuliia Savchenko-Shlapak}

https://orcid.org/0000-0002-1217-3190

e-mail:yo.savchenko@kubg.edu.ua

Institute of Arts, Borys Grinchenko Kyiv University, Kyiv, Ukraine.

The article examines the specificity of the development of creativity of adolescent students in educational musical activities. Various interpretations of the concept of "creativity" in relation to the peculiarities of adolescence of schoolchildren are analyzed. The creative nature of educational musical activity and its connection with the artistic nature of musical art are traced. The influence of problem learning methods, in particular situations of choice in educational musical activity, on development of creativity of adolescent schoolchildren. A specially designed situation of choice puts adolescents in conditions associated with the need to give preference to one of the options, to make an independent conscious choice.

Key words: creativity, adolescence, educational musical activity, problem learning, situation of choice. 
Introduction. The prevailing educational strategy around the world today is the strategy of forming a creative individuality, aimed at realizing the potential capabilities of each student, his creativity as an attribute of spirituality, the basis of self-expression and self-realization. The necessity and significance of the development of a person's creativity are dictated by several factors. First, globalization and the intensification of living space, when cardinal changes in the socio-cultural and industrial spheres require a high level of development of adaptive properties and human creativity. Secondly, a qualitative characteristic of the highest achievements in science, culture, production, which are primarily due to the high level of creative potential of their authors. Thirdly, the accelerated rate of renewal of scientific knowledge and the active introduction of modern information communication technologies in the daily life of people, which makes the problem of intensive development of the creativity of each person's personality a priority. Modern pedagogy is aimed at developing a creative personality. The concept of "creativity" is widely used in various social sciences, but in the context of the research will be considered in relation to the didactic process. For pedagogy, it is important to determine the focus and components of students' creativity in order to identify the content, forms and means of their most effective development. A significant contribution to the study of the problem of the development of creativity was made by domestic and foreign scientists (O. Antonova, L. Derevyana L. Dmitrieva, I. Lerner, E. Luzik, V. Pavlenko, V. Pavlyuk, N. Povyakel, O. Hamm and in.). In the works of scientists, attention is focused on the search for means of developing a person's creativity and methods of organizing his creative activity, the issues of developing creative abilities in educational activities are considered; methods of managing the creative processes of the intellectual activity of a person, technologies for diagnosing the creative 
abilities of students. The concept of creativity was developed by E. Ilyin, O. Rebriy, S. Sisoeva, A. Khutorskoy, E. Torrens (12). Research by scientists has proven that creativity is a common personality trait: ability, disposition, trait. With an IQ of 120 points and above, general intelligence and creativity form a single factor, with an IQ above 120 points, creativity becomes a factor independent of intelligence. A large and meaningful material has been accumulated on the study of creativity, however, no unified theoretical base, its general definition, as well as recognized methods that diagnose this ability have been found. The purpose of the article is to identify and substantiate the peculiarities of the development of creativity of adolescent schoolchildren in the lessons of musical art.

Presentation of the main material. Creativity is considered as creative possibilities (human abilities), which can be manifested in thinking, feelings, communication, certain types of activity, characterize the personality as a whole or its individual aspects, products of activity, the process of their creation, and as the most important and relatively independent factor of giftedness, which is rarely reflected in intelligence tests and academic achievement. Creativity is determined not so much by a critical attitude to new things in terms of existing experience, as by receptivity to new ideas. Researchers single out general intelligence among general abilities, less often - the ability to learn, and, finally, creativity. Among the various interpretations of the concept of "creativity", the following can be distinguished: creativity characterizes the level of creative giftedness, the ability to create, which is a relatively stable characteristic of a personality, unconscious to intellect; creativity is a function of a personality, depending on a whole complex of its psychological characteristics (16).

The concept of "creativity" was used by the English psychologist D. 
Simpson in 1922. This term denoted a person's refusal from stereotyped norms of thinking. Further, it appears in the works of American psychologists already in the second half of the 20th century to denote human abilities associated with creativity, the construction of something new (4).

The concept of creativity (creativity) was defined as the ability to be surprised and learn, the ability to find solutions in non-standard situations, focus on discovering new things and the ability to deeply understand their experience. According to this definition, the criterion of creativity is not the quality of the result, but the characteristics and processes that activate creative activity. An important stage in the study of creativity was the works of J. Guilford, in which the scientist identified two types of thinking convergent (logical, unidirectional) and divergent (going simultaneously in different directions, deviating from logic). Divergent thinking has a productive (creative) character with a high degree of novelty of the acquired knowledge. Divergent thinking allows for varying ways of solving a problem, leads to original, non-standard, unexpected conclusions and results. Divergent abilities are understood as abilities that give rise to a variety of original, equally correct ideas about the same object in an unregulated environment.

In the structure of creativity, scientists distinguish the following approaches: creativity as a personal category associated with selfdevelopment and self-actualization; creativity as a creative process; creativity as a result of activity associated with the creation of something new, as well as the following components: curiosity (non-verbal and verbal), spontaneity (comprehensibility as a personality trait); ease of language skills as a means of formulating thoughts. Creativity functions as a single holistic system. its development is conditioned by both social (macro, meso, micro), specific objective factors (type, type, sphere of creativity) and the 
peculiarities of the individual structure of creativity, in particular, the interaction of conscious (reflexive) and unconscious ( intuitive) processes $(4 ;$

Scientists distinguish naive and cultural creativity, where naive creativity is characteristic of childhood, in which there is no experience; cultural creativity consists in overcoming experience, in a conscious desire to avoid stereotypes and patterns of everyday consciousness and common sense. The formation and development of the creative abilities of an individual occurs only in a specially organized educational environment. Creativity must be taught - "... creative procedures, those structures that make up the essence of creative activity $(5,136-137)$.

Creative activity consists of: independent transfer of knowledge and skills to a new situation, vision of a new problem in a familiar situation, vision of a new function of an object and an alternative solution, determining the structure of an object, combining previously learned methods of activity into a new situation.

Creativity, emphasizing its versatility, is most often understood as various abilities, such as resourcefulness, originality, fantasy, intuition, the ability to solve problems, as well as "an integrative ability that incorporates whole systems of interconnected abilities - elements" (14, p. 121). Creativity is often compared to intelligence:

- separate creative abilities do not exist. The creative activity of a person is determined by his cognitive giftedness, motivation, values, sensitivity to problems, independence of actions in a situation of choice (A. Maslow, D. Bogoyavlenskaya, etc.);

- creativity exists independently and practically does not depend on intelligence $(5 ; 12 ; 14)$. There are creators with a low level of intelligence, but there are intellectuals with a low level of creativity;

- creative abilities are adequate to intellectual ones: the higher the 
creativity, the higher the intellect. There are no separate creative processes without corresponding intellectual processes.

The development of creativity is influenced by the individual characteristics of the individual, his emotional and mofanvatsyr. Creativity and personal development as a productive process of the opposite repoposal repoposal reproductive cheno-cenutitive chenuctitive chenuctitive chevititive. It is based on the assimilation of norms and adaptation to living conditions (including social ones): as a basis, motivation for achievement (success), the process of achieving a goal is provided with the help of stereotyped strategies and methods of behavior (action); the success / failure of achieving the goal is assessed using reinforcement feedback. If it is impossible to achieve the goal, as well as the emergence of danger on the way to its achievement (obstacle, conflict), the process is carried out in accordance with defensive strategies of avoidance. This behavior is characteristic of little gifted, uncreative people. The conditions that stimulate the development of creativity are listed:

- situations of incompleteness and openness, as opposed to rigidly set and strictly controlled; resolving and encouraging many questions (the ability to ask questions and fantasize);

- stimulation of independence, responsibility, independence (manifested together);

- emphasis on independent development, observations, feelings, generalizations);

- attention of teachers and peers to the interests of students.

As well as factors that hinder the development of creativity:

- risk avoidance, striving for success, by all means;

- rigid stereotypes in thinking and behavior; conformity;

- disapproving assessments of imagination, fantasy, admiration for authorities. An analysis of various interpretations allows us to conclude that 
creativity is a personal quality based on the potential capabilities of each person, the actualization of the unconscious need to be a unique individuality, free, but one that joins the general through the products of his creativity, harmoniously combines individual and social interests. Creativity as the optimal development of all potential capabilities of a person, as a general universal ability, is manifested and realized in the creative process. In our study, creativity is considered as an integrative personality quality, which includes the individual's creative abilities that affect self-determination and the creative nature of activity, is characterized by the readiness and ability to generate new unusual ideas, search for new approaches to solving known problems, formulation and solution of new problems, allows an individual to realize himself most fully in educational musical activity. The creativity of an adolescent schoolchild is manifested in interest, purposefulness and the need for him to make an independent decision in situations of choice, originality, search for non-standard alternative ways to solve a problem, independence in the process of implementing the selected task, independence of judgment, and the ability to predict the consequences of a choice. A sufficient level of development of the student's creativity will help him in mastering creative procedures for overcoming stereotypes in educational musical activity, which in turn will allow him to successfully realize himself in life as a person.

Adolescence is the transition from childhood to adulthood. During this period, attention to oneself, one's own peculiarities increases, the reaction to the opinions of others is aggravated, self-esteem and resentment increase. In adolescence, stable forms of behavior, character traits, and ways of emotional reaction are formed, formed. This is the time for achievements, the rapid increase in knowledge and skills, the acquisition of a new social position. At the same time, children's perception is lost, a feeling of anxiety and psychological discomfort appears. 
In adolescence, theoretical reflexive thinking continues to develop. The teenager already knows how to operate with hypotheses when solving creative problems. Faced with a new task, he is trying to find various approaches to its solution, which indicates the high possibilities for the development of such creative abilities, which are determined by flexibility of thinking and vigilance in search of problems. The teenager finds ways to apply abstract rules to solve entire classes of problems. This indicates a high potential for the development of the ability to transfer experience. The adolescent's mastery in the learning process of such mental operations as classification, analogy, generalization contributes to the effective development of the ability to converge concepts, is determined by the ease of analysis and remoteness of the analyzed concepts. The high quality of these indicators is determined by the features of theoretical reflective thinking, which allow adolescents to analyze abstract ideas. With the increase in intellectual development, the development of the adolescent's imagination also accelerates. Coming closer to theoretical thinking, imagination gives impetus to the development of creativity. The adolescent's imagination is less productive than the adult's imagination, but it is richer than the child's imagination. The peculiarities of adolescence are determined by specific social circumstances, first of all - a change in place in society, a change in position when entering into new relations with the world of adults, the world of their values, determines the new content of his consciousness.

Most often, creativity is considered as a general ability for creativity, which characterizes the personality as a whole, manifests itself in various spheres of activity and is considered as a relatively independent factor of giftedness. Creativity is actualized in certain conditions that must be created for each personality, taking into account its individual characteristics. In adolescence, creativity is suppressed for a number of reasons: social and 
personal limitations, fear of self-disclosure, negative reactions of society to personal manifestations. Teenagers have several opportunities to feel their own individuality and creativity. One of them is the development of one's personality on the model and likeness of the personality of an adult, since it is an adult in the eyes of a child who has independence, leadership abilities and social creativity. For the development and actualization of the creative abilities of adolescents, it is necessary to organize a special environment, which should have a high degree of uncertainty and potential variability (a wealth of opportunities). Uncertainty stimulates the search for their own landmarks, rather than the adoption of ready-made models. The possibility of finding them is provided by a lot of variance. In addition, such an environment should contain samples of creative behavior and its results.

Since the development of creativity in adolescence is important for the further development of a personality, the researchers have identified the most acceptable sphere for its manifestation in society. It was found that in adolescence the level of verbal creativity is higher than the level of nonverbal, and therefore the sphere of manifestation of verbal creativity creates more opportunities for organizing the creative environment and personal development of adolescents.

So, adolescence is a sensitive period in the development of creativity, which affects the formation of the personality as a whole, therefore, it is at this age that special attention should be paid to the development of creativity. On the one hand, adolescents show creative activity, on the other, the desire for self-expression and independence in solving problems. Modern training programs are designed to develop creative thinking, independence, initiative, however, in practice, the development and improvement of these skills does not take place in full.

The concept of "creativity" is closely intertwined with the concept of "creativity", but differ in meaning. Creativity is understood as a process that 
has a certain specificity and leads to the creation of something new. Creativity is considered as a potential, an internal resource of a person, his ability to abandon stereotypical ways of thinking, or the ability to find new options for solving problems, a person's ability to constructive, non-standard thinking and behavior, awareness and development of experience. The creative process is based on the author's inspiration, his abilities and traditions, while the main feature of the creative process becomes a pragmatic element - an initial understanding of why, why and how something needs to be created and, in fact, what needs to be created. Separating the concepts of "creativity" and "creativity", understanding creativity as an activity, and creativity as a general ability to creative activity, we believe that the creativity of schoolchildren should develop in educational activities.

In the scientific literature, educational activity is understood as a special form of social activity, manifested with the help of objective and cognitive actions; one of the activities of students aimed at assimilating theoretical knowledge and related skills and abilities in such spheres of social consciousness as science, art, morality, law and religion. The structure of learning activities includes learning situations, learning activities, monitoring and evaluation activities; motivation (cognitive need and need for self-development, interest in the content of educational activity), educational task (system of tasks, during the implementation of which the most common methods of action are mastered), educational operations (included in the method of action: operations and educational tasks are considered the main link in the structure of educational activity), control (on the part of the teacher and the student himself - self-control), assessment (adequate assessment). The development of creativity is influenced by the personal characteristics of the individual: knowledge, skills, skills are insufficient; the personality of a person is made by his 
attitude to reality, to people, to the environment, including knowledge. He becomes a person thanks to his purposefulness and worldview.

Let us consider the specifics of the development of creativity in the educational musical activity of adolescent schoolchildren. Music as art is an original phenomenon that has a powerful potential capable of developing creativity, which is distinguished by a pronounced personal content and manifests itself as a special ability to reproduce, interpret, and experience music. Creativity acts as an incentive force, predetermines the effectiveness of educational activities of students in the educational, teaching and developmental aspects. The creative nature of musical art is manifested not only in the creation, but also in the interpretation of musical works, opens up great opportunities for the development of personal creative qualities of students.

The creativity of a teenage student is a complex personal formation in which various areas of the psyche, properties and qualities are interrelated. With regard to the specifics of educational musical activity, the development of the creativity of adolescent schoolchildren is defined as a purposeful process of developing such personality traits as: interest, inclination to take risks, susceptibility to new ideas and knowledge, development of imagination, readiness to make choices in non-standard situations, independence of one's own opinion, manifestation flexibility in assessing the activities of other people, the ability to independent creative activity and focus on its result - the creation of an original creative product, obtaining a high-quality result that is distinguished by novelty. The highlighted creative personality traits correspond to the orientation of the selection procedure to actualize the students' motivation for creative activity. In the process of organizing educational musical activities for the development of the creativity of schoolchildren, it becomes necessary to use creative teaching methods. Exploring the pedagogical aspects of creativity A. Brushlinsky, I. 
Lerner (5), A. Matyushkin, M. Makhmutov consider the methods, conditions, methods, means of creative development of the individual.

The basic method used in modern didactics to develop creative abilities is problem learning. Problem-based learning has an activity-based nature; in the process of its implementation, knowledge is not transmitted in a finished form, but is obtained through independent activity in a problem situation. The method of problem learning is considered as a creative educational activity in which originality of thinking, ingenuity, combinatorics, intuition is manifested, leads to variability of actions, both mental and physical. In the structure of creativity, problematicity is one of its main parameters and is characterized as the ability to detect and pose problems. The active essence of problem-based learning is manifested in its general and special functions: assimilation of the methods of mental and practical activity, the development of cognitive independence and creative abilities, the upbringing of the creative potential of the application of knowledge, the formation and accumulation of experience in creative activity. This determines the relevance of problem-based learning in modern conditions of the development of pedagogy, focused on the development of creativity as an integrative quality of the individual.

The core of problem learning is a problem situation - an intellectual difficulty that arises when a person cannot or does not know how to explain a phenomenon, fact, process of activity, cannot achieve the goal in the ways known to him. Situations arising from problem learning require the mobilization of all the essential forces of a person, and not just reactive qualities. This makes it possible to distinguish the types of problem learning in accordance with the types of creativity. The first type is theoretical creativity: search and discovery of a rule, law, theorem; the second is practical creativity: the search for ways to apply known knowledge in a new situation. The third type of problem learning corresponds to artistic 
creativity, where the main way of reflecting reality is creative imagination. This type is most widely used in the process of teaching musical art (15).

Conclusions. So, we examined the specifics of the development of the creativity of adolescent students in educational musical activity, analyzed various interpretations of the concept of "creativity", examined the peculiarities of adolescence, discovered the creative nature of educational musical activity and its connection with the artistic nature of musical art, noted the influence of problem-based teaching methods, in particular situations of choice in educational musical activity on the development of creativity of schoolchildren of adolescence.

\section{References:}

1. Antonova, O.E. (2012). The essence of the concept of creativity: problems and searches Theoretical and applied aspects of the development of creative education in higher education. Zhytomyr: ZhSU Publishing House. I. Franko, 14-41.

2. Derevyana L. (2009). Creativity as a component of professional training of future social educators. Access mode:

http://www.nbuv.gov.ua/old_jrn/natural/vInu/Ped/2009_25-4/21_Dereviana.pdf.

3. Dmitrieva, L.D. (2007). Creative techniques for developing ideas. Access mode: www.elitarium.ru

4.llyin, E.P. (2012). Psychology of creativity, creativity, giftedness. SPb.: Peter, 830.

5.Lerner, I.Y. (1969). Search tasks in teaching as a means of developing creative abilities. Scientific creativity. Moscow: Nauka, 136-137.

6. Luzik, E.V. (2006). Creativity as a criterion of quality of the system of training of specialists of profile universities of Ukraine. Higher education of Ukraine, 3,76-82. 
7. Pavlenko, V.V. (2015). Teacher creativity as a factor in the development of pedagogical creativity. Formation of didactic competence of teachers of preschool and primary education: a collection of scientific and methodical works. Zhytomyr: ZhSU Publishing House. I. Franko, 145-150.

8. Pavlyuk, R. (2006). Criteria readiness of future educators to use a fairy tale in teaching a foreign language to preschoolers. Scientific achievements of students and undergraduates - schools of the XXI century: materials of the International scientific-practical conference. Poltava. Access mode: http://www.rusnauka.com/16_NPM_2007/Pedagogica/22154.doc.htm.

9. Povyakel, N.I. (2012). Practical psychology of creativity: a textbook. K.: Published by NPU named after MP Drahomanov, 321.

10. Rebriy, O.V. (2012). Modern concepts of creativity in translation: monograph. Kharkiv: KhNU named after V.N. Karazina, 375. Access mode: access:

http://ekhnuir.univer.kharkov.ua/bitstream/123456789/8879/2/monograph2012.pdf.

11. Sysoeva, S.O. (2006). Fundamentals of pedagogical creativity. K.: Millennium, 344.

12. Torrance, E.P. (1988) .The nature of creativity as manifest in the testing. Sternberg R., Tardif T. (eds.). The nature of creativity. Cambridge: Cambr. Press, 43-75.

13. Hamm, O. (2012). Theoretical bases of formation of creative thinking of the future teacher. Scientific works of IAPM, 2 (33), 255-259. Access mode: http://www.nbuv.gov.ua/old_jrn/Soc_Gum/Npmaup/2012_2/pdf_files/255259.pdf.

14. Khutorskoy, A.V. (2003). Didactic heuristics. Theory and technology of creative learning. M: Publishing house of Moscow State University, 121.

15. Chapaev, N.K. (2011). Creative pedagogy: problems, contradictions, ways to resolve them. Education and Science, 10 (69), 3-27. 
16. Shapar, V.B. (2005). Modern explanatory psychological dictionary. Kharkiv: Flag, 6.

Citation: Pan Qianyi, Regina Savchenko, Yuliia Savchenko-Shlapak (2021). EVELOPMENT OF THE CREATIVITY OF ADOLESCENTS IN LEARNING MUSICAL ACTIVITIES. New York. TK Meganom LLC. Innovative Solutions in Modern Science. 5(49). doi: 10.26886/2414-634X.5(49)2021.4

Copyright: Pan Qianyi, Regina Savchenko, Yuliia Savchenko-Shlapak @. 2021. This is an openaccess article distributed under the terms of the Creative Commons Attribution License (CC BY). The use, distribution or reproduction in other forums is permitted, provided the original author(s) or licensor are credited and that the original publication in this journal is cited, in accordance with accepted academic practice. No use, distribution or reproduction is permitted which does not comply with these terms. 